\title{
Learning to Create Sustainable Value in Turbulent Operational Contexts: The Role of Leadership Practices
}

\author{
Eng Chew \\ University of Technology, Sydney \\ P.O. Box 123, Broadway. NSW. 2007. \\ Australia \\ Ken Dovey* \\ University of Technology, Sydney \\ P.O. Box 123, Broadway. NSW. 2007. \\ Australia
}

\begin{abstract}
*Corresponding author. Contact details: Email: Ken.Dovey@uts.edu.au Telephone: 61-2-9514 7937

Fax: 61-2-9514 1807
\end{abstract}

\begin{abstract}
The capacity to create sustainable value has become a key differentiator of enterprise performance. This, however, is a complex task in rapidly transforming operational contexts. Under the umbrella term of 'dynamic capabilities' a range of practices has been identified in the literature as contributing to an enterprise's capacity to learn to perform this task successfully. In particular, 'ambidexterity' (the ability to manage contradictory exploit/explore strategies simultaneously) and 'absorptive capacity' (to ability to comprehend new knowledge quickly) are viewed as crucial to an enterprise's value-creation capability. This paper reports on research that explores the role of leadership practices in enhancing the dynamic capabilities of an enterprise. Based on case studies of three enterprises whose founders have sustained the creation of new value for customers over decades, several leadership practices are identified as critical to an organisation's capacity to learn continuously from a range of sources. The most important of these are the social practices that generate and leverage the intangible capital resources (in particular, the resource of trust) that underpin all collaborative learning and value creation processes.
\end{abstract}

Key Words Organisational learning; entrepreneurial leadership practices; dynamic capabilities; ambidexterity; absorptive capacity; value creation. 


\section{Learning to Create Sustainable Value in Turbulent Operational Contexts: The Role of Leadership Practices}

\section{Introduction}

As global competition for resources and markets intensifies, the capacity to create sustained value for customers is becoming a key differentiator of enterprise performance. In dynamic operational contexts, however, this vital aspect of competitive strategy is complex and requires considerable leadership nous and organisational agility. As a subjective phenomenon, the concept of 'value' is temporal and context-dependent with a broad range of socio-political factors, including that of human interests, playing a role in its apprehension. Furthermore, in increasingly volatile global contexts, the evanescent nature of 'value' necessitates continuous reconfiguring of organisational capabilities and renewal of knowledge bases. This makes the strategic challenge of constantly creating new value (innovation) a significantly difficult one to meet.

This paper documents an interpretative study aimed at gaining a deeper understanding of what successful enterprises do with respect to developing the learning and leadership capabilities required for continuous value-creation. Through case studies of three small medium enterprises (SMEs) that have successfully created new value for customers over periods ranging from twelve to thirty-three years, we have attempted to identify some of the practices that enable value creation in a range of uncertain and dynamic operational contexts.

We commence the paper with a review of the extant literature, followed by an outline of our research method. Thereafter, we provide a strategic narrative for each of the three case study firms; telling the story of their sustained growth over decades and describing the strategies upon which new value creation has been based. After discussing our analysis of the pertinent leadership practices shared by all three case organisations - practices that appear to have been instrumental in the successful conceptualisation and execution of value-creation strategies - we conclude by arguing for more research located within alternative research paradigms (to that of positivism) on this important topic.

\section{Literature Review}

While the word 'leadership' is well known our comprehension of the concept varies greatly according to our experience of the complex social phenomena referenced by this word. One complicating factor in achieving a shared understanding of this elusive concept is its contingent nature. As a social process it has multiple, emergent, contextual features that include the deep-structural influences of the cultural habitus (Bourdieu, 1977).

Historically, the positivist-dominated leadership research literature has focused primarily on individual competencies, traits and styles [see Gaines (2007) and Rodgers-Healey (2008) for an overview of this 
literature]. This has led to the broad acceptance of the 'heroic individual' model of leadership (Yukl, 2002). This literature, however, has struggled to define the term, as Stogdill (1974: 259) points out when stating that 'there are almost as many definitions of leadership as there are persons who have attempted to define the concept'. Bennis (1959: 259, quoted in Yukl, 2002, p. 3) concurs, arguing that:

the concept of leadership eludes us or turns up in another form to taunt us again with its slipperiness and complexity. So we have invented an endless proliferation of terms to deal with it ... and still the concept is not sufficiently defined.

More recently, some of the positivist literature has begun to concede the complexity of the phenomenon of 'leadership', with Jansen (2008:114) lamenting the little empirical evidence with respect to how senior executives are triggered to change levels of competence building and leveraging'. Similarly, after compiling their list of leadership competencies, Tom, van den Bosch and Volberda (2009) concede a socio-political dimension to leadership by arguing that a leader's capacity to learn is positively related to his/her decision-making authority (power) and connectedness to other organization members (social networks). Similarly, O'Reilly and Tushman (2011) raise the question about the role of socio-cultural practices in the development of individual competencies.

Another recent phenomenon has been a 'practice' turn in leadership studies, where the pre-eminence of the historico-cultural context in effective leadership practices has been strongly emphasised (Crevani, Lindgren \& Packendorff, 2010; Carroll, Levy \& Richmond, 2008; Whittington, 2006; Alvesson \& Sveningsson 2003). As Whittington (2006: 619) points out:

Practices refers to shared routines of behaviour, including traditions, norms and procedures for thinking, acting and using 'things', this last in the broadest sense.

In this literature, leadership is seen as a complex collective asset that is influenced strongly by past, present and future contextual phenomena. As yet, however, how such 'leadership' is developed, and how it manifests, in organisations that successfully sustain value creation over significant periods of time, is unclear. For example, the highly successful Brazilian company, Semco, has been the subject of much academic study in an attempt to understand how leadership manifests in this radical organisation in which the 'leader' refuses 'to take control' (Fisher, 2010). In spite of the high volume of research that has been conducted into this unusual company, little has become clear with respect to how leadership is enacted in it.

Another recent branch of literature explores the related concept of 'dynamic capabilities' and, although it does not explicitly link these to 'leadership practices', it endorses several collective practices that support a firm's ability to: (i) anticipate contextual changes, (ii) transform its current operations, and (iii) execute contradictory strategies simultaneously in order to serve old and new customers. This literature views such capabilities as being shaped by a firm's specific asset position (such as the firm's portfolio of difficult-to-trade knowledge assets and complementary assets) and the evolution path(s) the firm has adopted or inherited. Referring to these, Teece et al (1997: 509) argue 
that to sustain competitive advantage, a firm needs to learn how to 'to appropriately adapt, integrate and reconfigure its internal and external organizational skills, resources, and functional competences to match the requirements of a changing environment' (1997: 515). They, thus, are linking such capabilities to transformational practices; in particular, learning practices that build the collective capacity to anticipate, understand and enact whatever is necessary to sustain value creation in a dynamic social reality. Ten years later, Teese (2007) added another practice to the list of dynamic capabilities: the ability to sense and manage the opportunities and threats presented by a changing operational context. Hereby he implies the need for collective vigilance with respect to strategic inflection points that signal the need for strategic renewal and, where necessary, the reconfiguration of the firm's intangible and tangible assets so as to sustain value creation. In this, he is echoing the words of Eisenhardt \& Martin (2000: 1107) who claim that dynamic capabilities 'are the organizational and strategic routines by which firms achieve new resource configurations as markets emerge, collide, split, evolve, and die' (our emphasis).

Cohen \& Levinthal (1990: 128) introduce another practice that is vital to value creation; that of the 'absorptive capacity' of an organisational community. They define this as the 'ability ... to recognize the value of new, external information, assimilate it, and apply it to commercial ends' - and argue that it is an important antecedent to an enterprise's capacity to continually create value. Zahra and George (2002: 186) concur, adding that this concept has four fundamental dimensions: acquisition - capability to identify and acquire externally generated knowledge; assimilation - capability to analyse, process, interpret, and understand the external knowledge; transformation - capability to combine existing knowledge with the newly acquired and assimilated knowledge; and exploitation - capability to refine, extend, and leverage existing competencies or create new ones by incorporating the acquired and transformed knowledge into operations. They argue that an enterprise needs to balance or complement, and integratively configure, internal knowledge-creating processes with externallyoriented learning routines. Lewin, Massini and Peeters (2011: 81) agree, pointing out that innovation 'depends on the extent to which an organization evolves, adapts, and implements the configuration of its internal and external absorptive capacity routines'. In this respect, Noblet et al (2011) claim that enterprises that adopt and publicly commit to strategies of openness, and in which employees are encouraged to work with external partners, will build strong absorptive capacity in staff and, thereby, enhance innovation capability.

Another practice that is raised in this literature is that of 'ambidexterity', where sustainable value creation depends on a firm's ability to exploit its current capabilities (focused on efficiency in serving current customers) while simultaneously developing new capabilities (focused on flexibility/innovation in serving new, emerging customers). O'Reilly \& Tushman (2008: 190) define ambidexterity as the ability of an enterprise to align, coherently, 'competencies, structures and cultures to engage in exploration' while simultaneously managing 'a contrasting congruent alignment focused upon exploitation'. In this respect, Benner \& Tushman (2003: 252) point out that both sets of practices must coexist harmoniously in a strategically integrated manner. O'Reilly \& Tushman (2008: 193) concur, 
arguing that to capture the mutual benefits of exploitation and exploration, the firm must learn how to manage the contradictions and unite disparate sub-units by 'adopt[ing] a common fate incentive system and team processes capable of orchestrating strategic tradeoffs ... in a consistent fashion'. Similarly, Eisenhardt, Furr \& Bingham (2010) find that firms can learn to balance efficiency and flexibility through heuristics-based 'strategies of simple rules', and by engaging higher-order 'expert' cognition within multiple operational realities. To this set of leadership learning practices, Raisch et al (2009), add that of ensuring the continuous coalescence of external and internal knowledge bases, as also has been suggested by Lewin et al (2011).

In general, however, our knowledge of how leadership practices are developed and how they manifest in organisations and lead to sustained value creation over significant periods of time, remains limited. This paper seeks to make a small contribution to extending our understanding of such phenomena.

\section{Methodology}

Following Crotty (1998) and Burrell and Morgan (1979), we identified the epistemological and ontological assumptions that we held about this research before selecting an appropriate methodology. The epistemological assumption underpinning this research is that the knowledge we sought is subjective in nature and could only be accessed through inter-subjective means such as deeply-probing interviews (Crotty, 1998; Burrell \& Morgan, 1979). Furthermore, this knowledge is subject to the interviewee's interpretation and sense-making of her/his experience and, thus, has no objective 'truth'. While the process of interpretation can be enhanced through skilful probing by the interviewer, the interpreted knowledge will always be tentative and context-dependent. Furthermore, the ontological assumption (that is, the assumption about the nature of the reality within which the research is located) is that the social reality in which each person's experience has been acquired is nominalist in nature [see Burrell \& Morgan (1979) and Orlikowski \& Baroudi (1991) for more detail on the ontological and epistemological assumptions that underpin each of the various research paradigms]. As such, it is a 'political' reality that is co-constructed with other human beings and is subject to human interests, values, contestation, and other emergent contextual influences. Given these assumptions, this research was located within the interpretivist research paradigm [see Orlikowski \& Baroudi (1991); Crotty (1998); and Burrell \& Morgan (1979) for more details on this research paradigm].

The assumptions that underpin interpretivist research are radically different to those which underpin positivist research (traditional scientific research). Thus this emerging research paradigm, together with other relatively new research paradigms such as constructionism, is contesting the validity of positivist research within the social domain. These alternative paradigms assume that social reality is different to the natural reality (in which positivist research has been spectacularly successful) and that the dismal record of positivist research in the social domain (where humans have failed to discover 
the so-called general laws that govern social, economic and political systems) is a consequence of the inappropriate ontological and epistemological assumptions that underpin such research. These emerging research paradigms are thus challenging positivist assumptions on issues such as the possibility of the existence of objective social truths, general laws of human/social behaviour, and value-neutrality in social realities.

The knowledge that we were seeking through this research is that gained from the experience of learning to sustain value creation for customers over a long period of time (at least a decade) within turbulent socio-political and economic contexts. We thus set about finding people who had achieved this and, after a lengthy search, identified three entrepreneurs who satisfied our selection criterion, and conducted interviews with each. As we were attempting to access the privileged tacit knowledge that these three people had attained through rich and prolonged experience, we decided to adopt an interviewing technique that allows the interviewee to generate the constructs (rather than imposing the constructs through the use of interviewer-initiated, pre-conceived, questions) [see Kvale and Brinkmann (2009)]. Thus, after an initial request to 'tell the strategic story of the business', the interviewer probed each response for more detailed explication and explanation, with statements like: 'can you explain that further', 'what do you mean by that', 'can you give me an example', 'how did you feel about that', etc. As it is extremely difficult for anyone to articulate tacit knowledge, which often depends on contextual cues for it to manifest, conventional interviewing techniques cannot access this knowledge. However, through sensitive probing the interviewer delves deeper into the experiences of the interviewee, enabling her/him to access knowledge that would not normally 'come to mind' easily. In this way knowledge that is extremely 'sticky' [see Szulanski (1996) for the difficulties experienced in attempting to articulate tacit knowledge] becomes more accessible, allowing the interviewee to explore his/her experience more deeply.

Each interview, typically lasted around forty-five minutes, was transcribed and, in each case, a second interview was conducted in order to attain more refined explication of what we considered to be important practices that facilitated the knowledge creation (learning) and execution processes. The transcripts of both sets of interviews were analysed independently by the two researchers (authors of this paper) and those practices upon which there was consensus, were targeted for further explication in the second round of interviews. Following Heidegger (1996 edition), Stahl (1993) and Hunt (2011) we utilised the hermeneutic circle in our transcript analysis in order to achieve a rich understanding of the contextual forces within which the complex social practices, that underpinned the acquisition and effective deployment of the relevant knowledge bases, were formed (and/or transformed). This involved considerable effort on the part of the researchers to understand the parts of the text (transcript in this case) in relation to the whole, and vice versa. In this way, the interpretation of the meaning of the text was predicated on the researchers' understanding of the broad contexts of the interviewee's experience. Through such an analytical process, we hoped to make explicit the way that the privileged knowledge - that each interviewee has gained from experience and other forms of 
learning - was deployed in the execution of strategies aimed at sustained value creation for customers in dynamic operational contexts over lengthy periods of time.

\section{The Three Case Studies}

\section{$X Y Z$ - An Australian Manufacturing Company}

XYZ was founded by John in Sydney in 1981. Established as an importer/distributor of PVC pipes it later evolved into a water treatment products and solutions company. Prior to founding XYZ, John, an accountancy graduate with a keen interest in technical engineering matters, worked for nearly a decade in a family civil engineering business. According to him, 'this experience helped me understand engineering principles related to this field and kindled in me a passion for engineering and water treatment'. In this respect he recounts, 'my understanding of material procurement in the civil engineering business was instrumental in spotting an opportunity [an under-served market in Sydney] to import PVC pipes and fittings from Taiwan into Australia'. Focused initially on survival (with a staff of three), and guided by the broad strategic intent of becoming a player in water-related business, XYZ's strategic action followed a cycle of aim, act, learn and transform in accordance with customers' expectations and market movements. By 1987 the business had attained stability and was beginning to scale up. At that point John envisioned the BHAG (bold hairy audacious goal - see Porras \& Collins, 1994) of becoming a 'world-class water treatment company'. A couple of years later, XYZ was listed on the Australian Stock Exchange.

John's strategic moves were often triggered by opportunistic events and information provided by his strong social network. This information was 'evaluated' in terms of potential for business growth. As he puts it, 'each shift was to help improve existing business. Soon, the business extended to include plastic valves, which in turn led to a solar pool heating distribution business, followed by pumps and filters businesses'. Each of these iterations in the development of XYZ's dynamic capabilities was underpinned by John's new frames of reference with respect to better orchestration and integration of suppliers' capabilities and, thereby, to the development of XYZ's capacity to adapt to changing market needs. Following the 'complementarities' principle, an 'integrated swimming pool solution' was developed at $\mathrm{XYZ}$, and the company expanded into retailing (a new and potentially risky business proposition) in imitation of dominant market leaders. This stretched $X Y Z$ beyond its core competency of product distributor, and required the creation of a totally new, retailing, capability. Learning from a conference experience, John converted the $X Y Z$ retail outlets into a franchise model to make it scalable (growing it from 3 to 64 stores). Furthermore, the increasingly broad frames of reference with which John was leading the organisation led to a strategy of development through acquisition. In this initiative, John established two parallel streams of acquiring innovation capabilities from outside XYZ: (a) import from, collaborate with, learn from, and eventually acquire the selected strategically-aligned foreign suppliers of key products; (b) acquire domestic manufacturing capabilities in Australia as the opportunity arises to complement imports from overseas. Through this strategy John enabled XYZ to evolve into a 'fast follower and re-innovator'; allowing it to develop the 'winning' value proposition of its 
pumps: 'energy efficient quiet pump' integrated with 'pool design'. Furthermore, he configured supply chain management into a $X Y Z$ core competency, rapidly adapting integrated product lines and product features to emerging market needs.

John's learning strategy incorporated two forms of customer engagement: (i) informal contexts of engagement whereby customer problems are sensed/gathered through normal business interaction with the customers; and (ii) formal contexts of engagement whereby the sales and engineering functions and selected customers are involved in two annual product conferences to assess emergent customer needs and identify new product ideas (in this way, key social networks are affirmed and constantly renewed). An example of the informal innovation process is John's conversation with a French water treatment plant customer, in which a major problem was identified. Open to the complaint and sensing it as an opportunity for innovation, John thought that the problem may be solved by replacing the stainless steel-based system with a composite fiberglass-based system. Aligned with XYZ's strategic intent in the water treatment business, John decided to invest in R\&D of this customer-sourced product idea, without the need for feasibility or business case studies, while simultaneously pursuing incremental improvement of existing product lines. This turned out to be a three-year R\&D project and culminated in a European patent. Learning from this experience, John adopted the strategy of investing up to $25 \%$ of product development funds in 'high risk innovative product idea' experimentation. This enabled him to make swift strategic decisions when innovation opportunities arose.

\section{RST - An Australian Financial Services Company}

RST was founded in Sydney in 1979 by a 19-year old entrepreneur, Sue, serving as a broker 'matchmaking financier-to-borrower', based on the borrower's investment needs. Sue's initial focus was to maintain cash flow to keep the business afloat through an 'aim-act-learn-transform' type strategy. Once viable business scale was attained, this strategy was enhanced by a growth strategy of picking the 'right' external partners (those with the desirable capabilities to complement Sue's market knowledge) as co-owners of RST. As Sue's experiential frames of reference expanded, RST developed a staged-growth trajectory: the initial brokerage business (1979) expanded to include debit/credit managed services (1995) upon which a loan-serving back-office outsourcing service was established. Later this was extended into a lending business (2005) - first as a funds-manager by pooling investors' monies to serve as a bank-like money lender and second as a 'debt-recovery agent' of bad loans on behalf of lenders.

The first RST BHAG, envisioned when the business stabilized in 1990, aimed to make RST the fifth largest bank of commercial property in Australia by 2000. The opportunity to realise this BHAG was sensed by Sue in 1995 when the Australian government reformed Australian superannuation funds, resulting in an accelerated growth rate in mortgage funds. By then RST's organisational capabilities, and the associated intellectual capacity of its leaders, were sufficient to enable Sue to quickly take the initiative and 'commercialise' the new mortgage funds market opportunity. This success firmly established brokerage as RST's core business. At around the same time in 1995, an outside 
entrepreneur (Brian) shared with Sue the idea of establishing a debit/credit back-office managed service to offer to a new customer segment and thereby creating a new revenue stream. Based on experience (heuristic knowledge gained tacitly) Sue recognised the opportunity and agreed to partner (50:50 investments) with a competitor to create the necessary scale for developing the requisite new business capabilities, and to share risks/gains. This externally-sourced business innovation idea was implemented through judicious orchestration of the right resources for the new business unit, with Brian recruited as its head, while RST simultaneously exploited the core brokerage business. This new business unit proved successful and now operates as a mature business.

Always seeking new ideas, in 2005 Sue explored a new business option for funds management. This model aimed to serve borrowers who needed two mortgages either from the same or different financial institutions, each with a different yield/risk. However, as RST lacked the requisite capabilities and capital resources, Sue adopted a Joint Venture (JV) strategy to realise this innovative idea. The JV created a new, separate, business entity run by EFG while RST contributed credit management experts to work for, and learn from, the JV management team. This high risk (exploratory) strategy was conducted concurrently with the running of the other two (exploitative) businesses. More than $\$ 2 \mathrm{~m}$ was expended before some evidence of traction by the new business model was achieved. In 2010, once the business had become profitable, RST bought out EFG's share in the business and integrated it within RST as the third (funds management) business unit under Sue. This created the capacity to acquire competitors in 2008 , at the advent of the global financial crisis, and develop the funds-management business unit into a business innovation centre that explored new business model concepts and opportunities (such as direct access to super funds, and self-managed super funds) that were different but complementary to the existing mature businesses of brokerage and managed services. In support of RST's 'explore-exploit' strategy, Sue remarks that they have had to learn how to 'focus on managing cost (of mature businesses) while going for new revenue streams'.

\section{OP - A Global Business Process Outsourcing (BPO) Service Company}

Prior to founding OP, Clive managed the IT outsourcing function for a major Hong Kong bank. This was followed by $\mathrm{ClO}$ and General Manager (Information Services) roles for the Hong Kong Productivity Council. These executive roles enabled Clive to absorb external knowledge of Hong Kong's wide-ranging industries and internal knowledge of industrial-scale six-sigma-like lean production methodologies. Subsequently, in the late 1990s, Clive took up the coO role (as partowner) with an internet start-up named HIJ. According to Clive, these executive roles provided an ideal platform for learning how to address customers' exacting business requirements - a core capability for business process outsourcing service companies. Previously, during his $\mathrm{ClO}$ role at the Hong Kong Productivity Council, Clive had led a delegation of over one hundred Hong Kong investors to China, all focused on IT Foreign Direct Investment to, and industry engagement with, China. This experience sowed the seed of an idea about the potential of an ITO/BPO offshoring business and established the requisite social capital that would enable future leveraging of the resources (talent and government incentives) available from China. 
OP was co-founded in Hong Kong in 2000 by Clive but managed by partners while he continued to serve as $\mathrm{COO}$ of HIJ. This time Clive's experiential learning came from failure, as OP was run to ground by Clive's partners in 2003. To rescue the company, Clive sold off HIJ and reinvested in OP, taking over the CEO role. He reconfigured OP into a Linux multi-lingual hardware manufacturer and, although the hardware business appeared to miss the markets, fortuitously its multi-lingual processing capabilities attracted the attention of a former United States BPO executive. Switching focus to multilingual services, Clive redirected OP strategy and orchestrated/integrated two sets of complementary core capabilities to create a new BPO business in partnership with the US executive. Enabled by his intangible capital resources developed through diverse social networks, and the China-sourcing knowledge gained in previous executive roles, Clive transformed OP into a China-based, cost-leader data entry BPO service provider, initially targeting the US market and winning OP's first US customer.

To improve service delivery reliability and enhance customer relationships, Clive developed 'homebrew' workflow software, a radical OP innovation which was co-designed with US customers. Based on the customer internal process, it simplified customer activities and improved service quality through data entry automation and minimising human errors. The cost reduction achieved as a result of the success of this IT-enabled service innovation, was passed on to customers in recognition of their role in the knowledge creation process.

Improved quality and reduced costs delighted OP's US customers. Business grew through referral and soon was extended to new services of database entry and medical insurance claims. A crisis, however, occurred in 2005 when the US partner died suddenly. Fortunately, Clive's strong social capital with the US partner's family and other US customers enabled the graceful transition of OP ownership fully to Clive and the retention of all US customers. This assured OP's survival as an international firm with a US office.

Clive continued to explore opportunities to innovate and, consequently, developed a new optical character recognition service with a view to digitizing US genealogical documents. This proved highly successful and was integrated into OP's core business, together with a multi-lingual handwriting recognition data entry service for insurance claims, purchase orders, and translating fax and email order into standard data format for automated processing. Gradually OP became global with revenues from the US, Europe and Asia. In 2009/10, Clive began to engage OP grass-root employees in envisioning OP's BHAG to become The Infosys of China; a vision that required the development of merger and acquisition capabilities. Clive launched and led these M\&A exploratory activities - yet again demonstrating OP's capacity for ambidexterity.

At this point, Clive took direct responsibility for the development of the learning capabilities and knowledge growth of OP's staff. He personally managed the training of new hires, focusing on the shared values and cultural norms that underpin OP's capacity to learn and innovate. A balanced 
scorecard was enacted to ensure consistent company-wide self-reflexive execution of OP strategies. Collaborative learning forums (which included customers) were introduced and team performance was incentivised to engender high quality and reliable service delivery. Basing the OP knowledge management infrastructure on a Skype-powered social network, he enabled company-wide communication, coordination and knowledge sharing, with each department documenting its domain knowledge and an editor integrating this into a company-wide knowledge base. This social-mediabased explicit knowledge sharing is complemented by Skype-based network-sharing of tacit knowledge to enhance OP's organizational learning and dynamic capabilities. In 2011, OP successfully merged with a large Chinese ITO company to become an 18,000-employee ITO/BPO corporation, with Clive leading the new BPO strategic business unit. Through this new entity, OP is well on its way toward realizing its BHAG.

\section{Discussion}

Although the strategic narrative of each case is centred upon the role of the founder/CEO in the development of the dynamic capabilities of each organisation, the interview data reflects broader social forces at work, thus endorsing the 'practice turn' in leadership studies. In each case, organisation-wide openness to ideas and information ensured the early detection of strategic inflection points (changes in the operational context and/or customer behaviour, the advent of new technologies, emerging customer needs, etc.) and the creation of vital frames of reference that enabled the absorptive capacity of the collective to grow at a rapid rate. This appears to be part of the 'shared routines of behaviour, including traditions, norms and procedures for thinking and acting' referred to by Whittington (2006, p. 619) that characterises a collective practice. Similarly, the finding on the role of broad information flows, facilitated by intellectual openness and generosity, in the creation of the rich frames of reference which underpin growing absorptive capacity, endorses the work of Noblet et al, (2011) in this domain.

Furthermore, in each case, an informal form of praxis (exemplified by the self-reflexive process of 'aim, act, learn, transform' wherein strategic vigilance, action and learning are enacted) enabled the collective capacity to learn from a broad range of experiences. This collective practice ensured the conversion of rich tacit knowledge, gained from taking action, into strategically valuable explicit knowledge that was used to renew and/or recreate strategic direction and execution. Furthermore, the building of tacit knowledge bases, with respect to organisational transformation, enhanced the effective management of the politics and challenges of continuous change. The extant literature is relatively silent on this crucial social practice probably because of the alternative epistemological assumption that is embedded in praxis as a practice - that is, the assumption that certain forms of knowledge can only be acquired through action (as a 'way of knowing'). This implies that alternative research paradigms, such as that of constructionism, are more likely to deliver new insights on the role of such practices in the creation of value. 
Perhaps the most important point communicated by the interview data is the value of social capital to collective endeavour. In each case, through access to key relationship-based intangible capital resources (particularly resources such as 'trust' and 'ideas') these organisations were able to exercise unusual vigilance with respect to business opportunities. In addition, their (trust-based) porous organisational boundaries allowed the free flow of the conceptual capital (ideas and knowledge) necessary for continuous organisational and personal renewal, across extensive social networks (on the value of social capital to resource exchange, see Nahapiet \& Goshal, 1998).

Another feature of all three cases is the absence of the hubris that often accompanies organisational success [see Owen and Davidson (2009) and Sarason (1972)]. Within each organisation, the limits of existing stakeholder knowledge with respect to new ventures and opportunities were recognised and addressed. Such intellectual humility enabled each firm to engage in life-long learning from direct and indirect experience, with decision-making in all three enterprises being based on experientiallyderived insights and social network generated information. While a degree of risk was built into all decisions, the close monitoring of strategic action and the readiness to transform it (and the assumptions upon which it was based) enabled that risk to be managed through strategic vigilance and 'double-loop learning' (see Argyris \& Schon, 1996). Such exercises in intellectual humility underpinned the organisational capacity to renew knowledge bases constantly and to cherish trusting relationships among stakeholders and the broader business community.

\section{Summary of Results}

The data reflects four social practices that have, in particular, contributed to mission-pertinent knowledge creation, and its successful deployment, within these enterprises:

1. Each case demonstrates exploratory practices that exemplify openness to ideas irrespective of their source, with a view to continuous organisational redesign/improvement through learning from experience with customers.

2. Each case highlights self-reflexive practices that incorporate contextual vigilance and the regular evaluation of, and learning from, strategic execution and organisational transformation if necessary.

3. In all three enterprises stakeholders are preoccupied with maintaining the currency and growth of social capital (trusting relationships with business partners, staff, customers, suppliers, industry experts, regulators, competitors, and adjacent industry experts). The leveraging of this social capital underpins the effectiveness of orchestration practices through which internal and external resources are reconfigured, via insource, outsource and/or jointventure strategies, to co-create superior customer value.

4. Each case demonstrates the role of collective 'intellectual humility' in continuous value creation. In spite of business success, the practice of life-long learning from experience and from others, deeply informs the processes of value creation and strategic innovation in these enterprises. 


\section{Conclusion}

The results of this study have at least two important implications for practice. Firstly, in the complex operational contexts of business organisations in the $21^{\text {st }}$ century, the notion of the 'heroic individual' as leader, or creator of sustained value, no longer has currency. Our results indicate that leadership is increasingly enacted by a broad body of stakeholders through a set of taken-for-granted practices (or routines) underpinned by shared commitment to learning, transforming (on the basis of that learning) and delivering sustained value to customers. In this sense, our results endorse much of the 'dynamic capabilities' literature. Secondly, this set of practices is formed over a considerable period of time through consistent endorsement thereof by key stakeholders (particularly those with power) whose on-going presence is an important constant in the otherwise evanescent nature of the enterprise. In this way, individuals do influence the nature of leadership practices but such influence occurs over time and circumstance, as the future is collectively anticipated and addressed through forums that facilitate cycles of awareness, action, learning, and reflection.

Furthermore, our results place far greater emphasis on the importance of relationships, and the access they provide to vital intangible capital resources, than is the case in the current literature on value creation. In all three case studies, the value creation practices 'that matter' are embedded in stakeholder and community relationships. In particular, our results show that strategic vigilance and absorptive capacity are strongly dependent upon the experiential frames of reference that are built, directly or indirectly, through social network ties. This has important implications for the way that business leaders prioritise their actions and view themselves in that hubris does not encourage the intellectual humility necessary for learning.

One possible reason that relationships and, by implication, the important role played by intangible capital resources in value-creation processes, are relatively neglected in the literature is that the vast majority of research in this area is located within a positivist paradigm. Given the alternative ontological and epistemological assumptions, with respect to social realities, that underpin interpretivist and constructionist research, more research located within these two research paradigms seems necessary for the effective exploration of the leadership practices that underpin the dynamic capability of continuously creating value for customers.

\section{References}

Alvesson, M. and Sveningsson, S. (2003), "The great disappearing act: Difficulties in doing 'leadership'", The Leadership Quarterly, Vol.14 No. 3, pp. 359-81.

Argyris, C. and Schon, D. (1996), Organizational Learning II: Theory, Method and Practice, AddisonWesley, Reading, MA).

Benner, M. J. and Tushman, M. L. (2003), "Exploitation, exploration and process management: The productivity dilemma revisited", Academy of Management Review, Vol. 28, pp. 238-256.

Bourdieu, P. (1977), Outline of a Theory of Practice, Cambridge University Press, Cambridge, UK. 
Burrell, G. and Morgan, G. (1979), Sociological Paradigms and Organizational Analysis: Elements of the Sociology of Corporate Life, Heinemann, London, UK.

Carroll, B., Levy, L. and Richmond, D. (2008), "Leadership as practice: Challenging the competency paradigm", Leadership, Vol. 4 No. 4, pp. 363-79.

Crevani, L., Lindgren, M. and Packendorff, J. (2010), "Leadership, not leaders: On the study of leadership as practices and interactions", Scandinavian Journal of Management, Vol. 26, No.1, pp. 77-86.

Cohen, W. M. and D. Levinthal, D. (1990), "Absorptive capacity: A new perspective on learning and innovation", Administrative Science Quarterly, Vol. 35, pp. 128-152.

Crotty, M. (1998), The Foundations of Social Research: Meaning and Perspective in the Research Process, Allen \& Unwin, Sydney, NSW.

Eisenhardt, K. M., Furr, N. R. and Bingham, C. B. (2010), "Microfoundations of performance: Balancing efficiency and flexibility in dynamic environments", Organization Science, Vol. 21 No. 6, pp. 1263-1273.

Eisenhardt K. and Martin J. (2000), "Dynamic capabilities: What are they?", Strategic Management Journal, Special Issue 21, pp. 1105-1121.

Fisher, L. (2010), "Ricardo Semler won't take control”, Strategy \& Business, Vol. 41, pp.1-11.

Gaines, K. (2007), A Communicative Theory of Leadership Practice. PhD Thesis, Antioch University, Los Angeles, USA.

Heidegger, M. (1996 edition), Being and Time, translated by Joan Stambaugh, State University of New York, New York.

Hunt, S. (2011) Understanding Learning Within Information Technology Projects: An Examination of the Australian Experience. PhD Thesis, University of Technology, Sydney, Australia.

Jansen, J. J. P. (2008), "Combining competence building and leveraging: Managing paradoxes in ambidextrous organizations", Advances in Applied Business Strategy, Vol. 10, pp. 99-119.

Kvale, S. and Brinkmann, S. (2009), Interviews: Learning the Craft of Qualitative Research Interviewing, $2^{\text {nd }}$ Edition, Sage, Los Angeles.

Lewin, A. Y., Massini, S. and Peeters, C. (2011), "Microfoundations of internal and external absorptive capacity routines", Organization Science, Vol. 22 No. 1, pp. 81-98.

Nahapiet J. and Ghoshal S. (1998), "Social capital, intellectual capital and the organizational advantage", Academy of Management Review, Vol. 23 No. 2, pp. 242-266.

Noblet, J-P., Simon, E. and Parent, R. (2011), "Absorptive capacity: A proposed operationalization", Knowledge Management Research \& Practice, Vol. 9, pp. 367-377.

O'Reilly, C. A. and Tushman, M. L. (2008), "Ambidexterity as a dynamic capability: Resolving the innovator's dilemma", Research in Organizational Behavior, Vol. 28, pp. 185-206.

O'Reilly, C. A. and Tushman, M. L. (2011), "Organizational ambidexterity in action: How managers explore and exploit", California Management Review, Vol. 53 No. 4, pp. 5-22.

Orlikowski, W. and Baroudi, J. (1991), "Studying information technology in organizations: Research assumptions and approaches", Information Systems Research, Vol. 2 No. 1, pp 1-28. 
Owen, D. and Davidson, J. (2009), "Hubris syndrome: An acquired personality disorder? A study of US Presidents and UK Prime Ministers over the last 100 years", Brain, Vol. 132, No. 5, pp. 13961406.

Porras, J.I. and Collins, J.C. (1994), Built to Last: Successful Habits of Visionary Companies, HarperBusiness, New York, NY.

Raisch, S., Birkinshaw, J., Probst, G. and Tushman, M. L. (2009), "Organizational ambidexterity: Balancing exploitation and exploration for sustained performance", Organization Science, Vol. 20, No. 4, pp. 685-695.

Rodgers-Healey, D. (2008), Abandoning the Masculine Domain of Leadership to Identify a New Space for Women's Being, Valuing and Doing, PhD Thesis, University of Wollongong, Wollongong, Australia.

Sarason, S. (1972), The Creation of Settings and the Future Societies, Jossey-Bass, San Francisco, CA.

Stahl, G. (1993), Interpretation in Design: The Problem of Tacit and Explicit Understanding in Computer Support of Cooperative Design. Viewed 15 January 2011, <http://gerrystahl.net/publications/dissertations/computer/index.html>.

Stogdill, R. (1974), Handbook of Leadership: A Survey of Theory and Research, Free Press, New York, NY.

Szulanski, G. (1996), "Exploring internal stickiness: Impediments to the transfer of best practice within the firm", Strategic Management Journal, Vol. 17, Special Issue, pp. 27-43.

Teece, D. J. (2007), "Explicating dynamic capabilities: The nature and microfoundations of (sustainable) enterprise performance", Strategic Management Journal, Vol. 28, pp. 1319-1350.

Teece, D. J., Pisano, G. and Shuen, A. (1997), "Dynamic capabilities and strategic management", Strategic Management Journal, Vol. 18, pp. 509-533.

Tom, T., van den Bosch, F. and Volberda, H. (2009), "Understanding variation in managers' ambidexterity: Investigating direct and interaction effects of formal structural and personal coordination mechanisms", Organization Science, Vol. 20 No. 4, pp. 812-828.

Whittington, R. (2006), "Completing the practice-turn in strategy research", Organization Studies, Vol. 27 No. 5, pp. 613-34.

Yukl, G. (2002), Leadership in Organizations (5th ed.), Prentice Hall, Upper Saddle River, NJ.

Zahra, S. A. and George, G. (2002), "Absorptive capacity: A review, reconceptualization, and extension", Academy of Management Review, Vol. 27 No. 2, pp. 185-203. 